Wildy, P. (1955). J. gen. Miorobiol. 13, 346-360

\title{
Recombination with Herpes Simplex Virus
}

\author{
By P. WILDY* \\ The Walter and Eliza Hall Institute of Medical Research, Melbourne, Australia
}

SUMMARY: The behaviour of six strains of herpes simplex virus was studied. Marked differences were noted in the type of lesion formed and the rate of attachment when the strains were inoculated on to the chorio-allantois, and in the behaviour of strains inoculated intracerebrally into mice or on to the cornea of the rabbit.

Two easily differentiated strains were inoculated together on to the chorio-allantois under conditions designed to give rise to a proportion of doubly infected cells. After a short period of incubation the progeny of the first intracellular growth cyele was obtained.

Ten clones were isolated, of which six resembled one of the two parents in the type of lesion formed and level of virulence for mice. Of the other four, one (106a) produced small type lesions and the other three large type. All possessed degrees of virulence intermediate between those of the parents. Three of these substrains showed no alteration in the type of lesions formed or their degrees of virulence after 3 to 5 passages of single lesions at limiting dilution. When the rate of attachment to the chorio-allantois and the behaviour when inoculated on to the cornea of the rabbit were studied, it was found that 106 a produced effects intermediate between the parents, whilst the other strains resembled one of the two parents.

Genetic recombination has now been demonstrated amongst several viruses. Delbrück \& Bailey (1946) and Hershey \& Rotman (1948) showed genetic interaction with bacteriophage. More recently, conclusive evidence of recombination has been provided amongst the influenza viruses (Burnet \& Lind, 1951; Burnet, Fraser \& Lind, 1953; Hirst \& Gottlieb, 1953; Perry, van den Ende \& Burnet, 1954). No animal virus other than influenza has yet been shown to exhibit this type of genetic interaction. The object of the present work was to discover whether herpes simplex virus would recombine when subjected to conditions like those required for recombination in other viruses. Before this was attempted, a study was made of the characteristics of six strains of herpes virus in order to find suitable markers by which to identify the progeny.

\section{MATERIALS AND METHODS}

Virus strains. Six strains of herpes simplex virus were used. One strain (Eri) was recently isolated from a case of labial herpes and was used after six passages on the chorio-allantois. The other five have been maintained in the stocks of the Walter and Eliza Hall Institute for some years. The strain H.F.E., which had been adapted to grow on the chorio-allantois by Burnet \& Lush $(1939 a)$ originated from the Rockefeller Institute strain H.F. The mouseadapted strain H.F.E.M. had been adapted from strain H.F.E. and is not directly descended from the mouse-adapted strain described by Burnet \& Lush

* Present address: Department of Bacteriology, St Thomas's Hospital Medical School, London, S.E. 1 . 
$(1939 b)$. The remaining strains Nag, Sch and W.C. have been isolated over the years at this Institute.

Maintenance of strains. The strain H.F.E.M. had been maintained by intracerebral passage in mice; all other strains had been maintained by chorioallantoic passage. Suspensions of virus used were first obtained as pure clones by the method outlined below. All strains were then passaged once on the chorio-allantois from which suspensions were made by grinding with alundum. These suspensions were stored at $-70^{\circ}$ in ampoules.

Diluting fluid. All dilutions of virus were made in broth (Wright, 1933) to which was added streptomycin and penicillin to give respectively $200 \mu \mathrm{g} . / \mathrm{ml}$. and 14 units $/ \mathrm{ml}$.

Egg techniques. The conventional egg techniques used were those described by Beveridge \& Burnet (1946). All titrations of infectivity for eggs were made with serial tenfold dilutions of virus and inoculating each on to the chorioallantois of four eggs at the 11th or 12th days of incubation. The infective unit (i.u.) is defined as the quantity of virus necessary to give rise to one lesion on the chorio-allantois after incubation at $35^{\circ}$ for $48 \mathrm{hr}$.

The rate of attachment of virus to the chorio-allantois was measured as previously described (Wildy, 1954). Briefly, $0.05 \mathrm{ml}$. virus suspension was inoculated on to the chorio-allantois of a number of eggs at a dilution which gave 50 to 100 lesions/membrane. After the required period, the proportion of virus remaining unattached was determined in eight of the eggs. To each egg, $0 \cdot 1 \mathrm{ml}$. broth was added and the hole in the shell obliterated with paraffin wax. The egg was then rotated about its long axis through $120^{\circ}$. This manoeuvre drives the bubble of air in the artificial airspace to a new position, and the fluid containing unattached virus is carried to a new area on the chorio-allantois. After incubation at $35^{\circ}$ for a further $48 \mathrm{hr}$. the membranes were removed intact and the lesions counted on both the first and second areas.

Isolation of pure clones. It has been assumed that any specific lesion formed on the chorio-allantois is caused by one virus particle. On this assumption, the validity of which will be discussed later, pure clones were isolated by grinding lesions formed at limit dilution, that is where lesions occurred singly per membrane.

Specific neutralization. Herpes neutralization tests were carried out using the method of Burnet \& Lush (1939a). For this purpose and for removing unwanted extracellular virus in the recombination experiment, the serum used was derived from rabbits which had been immunized against strain H.F.E. (Wildy, 1954).

Animal techniques. Mice of the Walter and Eliza Hall Institute stock strain were used during the fourth week of life. Titrations of virus were made by inoculating tenfold dilutions of virus suspensions each into four mice. Each mouse received $0.05 \mathrm{ml}$. virus intracerebrally. The mice were observed over a period of 14 days and all deaths in mice showing signs of encephalitis were regarded as specific. The end-points taken were at the dilution of virus required to give $50 \%$ mortality (LD 50), which was calculated by the method of Reed \& Muench (1938). 
The degree of virulence for mice was measured by making parallel titrations of suspensions of virus in mice and in eggs, using the same set of dilutions for each. From the values obtained, the degrees of mouse virulence have been expressed quantitatively as the mouse virulence ratio (m.v.r.). This value is defined as the number of infective units required to constitute one $50 \%$ lethal dose for the mouse under the conditions of the test (i.e. m.v.r. =i.u./LD 50). It may be noted that this value varies inversely with the virulence of the strain for mice.

Rabbits were inoculated as young adults by scarification of the cornea whilst under ether anaesthesia, followed by the instillation of $0.05 \mathrm{ml}$. virus suspension containing from $10^{4}$ to $10^{5} \mathrm{i} . \mathrm{u}$. They were then observed for a period of 14 days.

\section{RESULTS}

Characterization of six strains of herpes simplex virus

In order to find two strains with readily and clearly defined marker characteristics, a study was made of the behaviour of six strains of herpes simplex virus, the relevant features of which are recorded in Table 1.

Serological uniformity. All the strains were tested for specific neutralization by the method of Burnet \& Lush (1939a). In every case, the serum which had been prepared against H.F.E. neutralized the virus.

Preliminary experiments had shown that the six strains behave differently in eggs. The character of the lesion produced, the rate of increase of infective virus and the rate of attachment to the chorio-allantois all differed from strain to strain.

Character of the lesions. The character of the lesions formed was investigated by inoculating a number of eggs each with 50 to $100 \mathrm{i} . \mathrm{u}$. of the strain in question and incubating at $35^{\circ}$. At daily intervals, four eggs were taken and the lesions carefully examined. It was found that the four strains H.F.E.M., H.F.E., Sch and Eri caused large opaque lesions (LO lesions) and these are referred to subsequently as LOL strains. These lesions generally measured 1.0-1.5 mm. diameter, but the size varied from egg to egg and to some extent inversely with the number of lesions on the membrane. The other two strains Nag and W.C. gave small lesions (S lesions) which never exceeded $0.5 \mathrm{~mm}$. diameter. These are subsequently referred to as SL strains. With the LO lesions there was a tendency for the centres of a proportion of them to become necrotic and sometimes haemorrhagic. This was common after incubation for $48 \mathrm{hr}$. and constant after $72 \mathrm{hr}$.-S lesions, on the other hand, never became necrotic, even after incubation for 5 days. In fact it was always possible to tell at once with which type one was dealing. Membranes showing typical lesions are depicted in $\mathrm{Pl}$. 1 .

Extent of multiplication in $48 \mathrm{hr}$. The extent of multiplication in the chorioallantois was estimated by inoculating 50-100 i.u. on to the chorion and harvesting the membranes after $48 \mathrm{hr}$., but because the membranes were ground with alundum, the results are regarded as being very approximate (cf. Anderson, 1954). It was, however, obvious that the LOL strains gave increases which were more than 100 times those of the SL strains. 


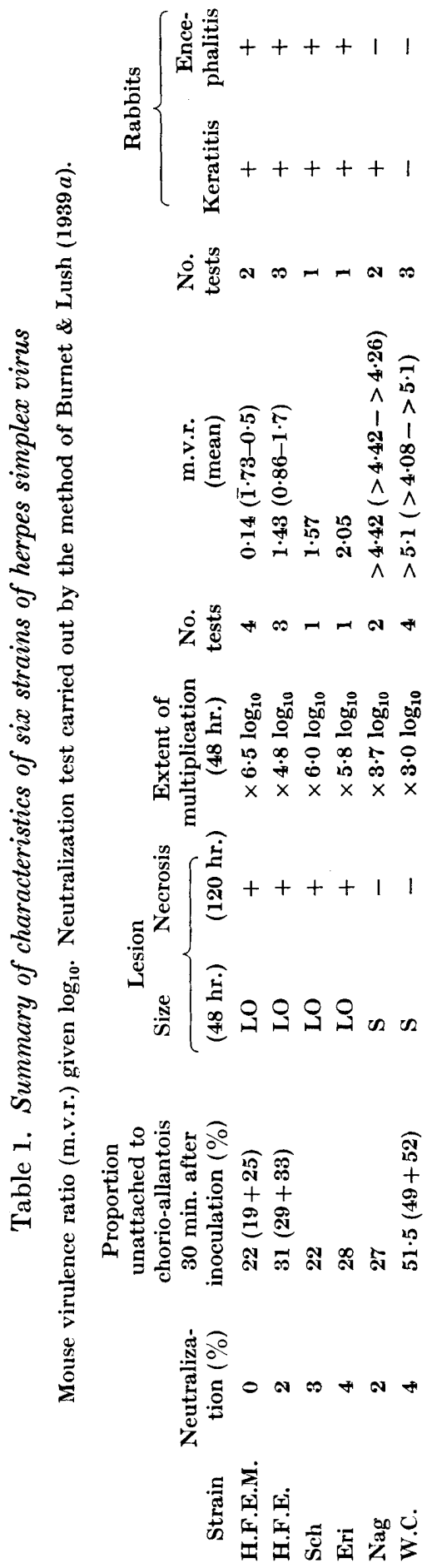


Rate of attachment to the chorio-allantois. The proportion of virus remaining unattached was determined 30,60 and $120 \mathrm{~min}$. after inoculation. It was found that there was little difference between the strains H.F.E.M., H.F.E., Sch, Eri and Nag, where the proportion of virus remaining free was at 30,60 and 120 min., respectively, 22-31, 7-13 and 4-10\%. On the other hand, W.C. became attached much more slowly, the equivalent values being 50.5, 30 and $20 \%$. Only the $30 \mathrm{~min}$. values are given in Table 1 .

Virulence for mice. The virulence for mice was determined as described above. With strains H.F.E.M., H.F.E., Nag and W.C. separate determinations were made with suspensions of virus derived from successive passages on the chorio-allantois. It may be seen in Table 1 that the LOL strains all gave rise to encephalitis and death in mice, whilst the SL strains (Nag, W.C.) never showed this potentiality in the concentrations tested. Moreover, the degrees of virulence of the LOL strains are distinct, decreasing in the order given. It is also apparent that the strains which were tested upon more than one occasion gave a range of m.v.r. of a little less than a $\log _{10}$ unit.

Behaviour in rabbits. Of a number of animal species tested for susceptibility to infection, clear-cut differences were only observed with the rabbit when inoculated on the cornea. The results were as follows. All the strains except W.C. produced visible keratitis in the inoculated eye within 2-4 days. Of these, all except strain Nag gave severe conjunctivitis, blepharitis and encephalitis and death within 7-11 days of inoculation. It is of interest that Nag gave rise only to keratitis whilst the other SL strain, W.C., gave rise to no visible abnormality.

Table 1 summarizes the main characteristics of the six strains studied. Differences of a similar sort have been reported previously by several authors (Burnet \& Lush, 1939 b; Florman \& Trader, 1947; Kilbourne \& Horsfall, 1951). It is of interest that all the LOL strains produced encephalitis either in rabbit or in mouse. These LOL strains all multiplied to a similar extent within $48 \mathrm{hr}$. and all were capable of producing lesions with a central necrotic crater. The SL strains, on the other hand, did not produce encephalitis, multiplied more slowly and never produced necrotic lesions.

When the rate of attachment to the chorio-allantois and the production of keratitis in the rabbit are considered, the demarcation comes in a different place. The LOL strains and Nag all give keratitis and become attached rapidly; strain W.C. which gives no clinical keratitis and become attached more slowly.

It has been possible to measure the virulence for mice of the $L$ strains on a quantitative basis. When the results of this test are combined with the foregoing results, it is possible to arrange the six strains in a definite order of 'activity' as they are given in Table 1.

\section{General plan of the recombination experiment}

Of the six strains which had been studied, H.F.E.M. and W.C. were chosen as prospective parents. Although this choice introduced difficulties which will become apparent below, it did make use of the strains available which were the most widely different. Before recombination was attempted, two essentials had to be satisfied: (1) the ratio infective virus/susceptible cells had to be great 
enough to ensure that a proportion of susceptible host cells were doubly infected with both parents; (2) a method had to be devised for obtaining virus from the first intracellular growth cycle which was not contaminated with unincorporated virus.

\section{Multiple infection of cells.}

Of the tissues available in which herpes virus will grow, the chorio-allantois is probably the simplest to use. It possesses the advantages that infection may be restricted to a small area of its surface and that reagents may be placed upon it with ease. Tyrrell, Tamm, Forssman \& Horsfall (1954) estimate that the total number of cells in the allantois is about $10^{7 \cdot 25}$. But for our purpose it is better to use the higher estimate of $10^{8.3}$ made by Cairns, Fazekas de St Groth \& Edney (1952). It has been assumed that the number of cells in the entire chorion is of a similar order, but because only about one-eighth of the total chorion is exposed to infection, it is safe to assume that the cell content of the infected portion is about $10^{7 \cdot 25}$. Thus more than $10^{8} \mathrm{i} . \mathrm{u}$. virus should suffice to ensure multiple infection of a proportion of cells.

It was found possible to obtain suspensions of strain H.F.E.M. which contained adequate concentrations of virus by inoculating into the yolk sacs of eggs at the eighth day of incubation and harvesting the amniotic fluids after a period of further incubation at $35^{\circ}$ of 4 days (Nagler, 1946). With strain W.C., on the other hand, it was not found possible to obtain suitable concentrations of virus by this means alone. Adequate concentrations were, however, obtained by collecting the amniotic fluids from 100 eggs which had been inoculated in this way and centrifuging for $60 \mathrm{~min}$. at $12,000 \mathrm{~g}$. on a Spinco preparative ultracentrifuge.

\section{Method of obtaining the progeny of the first intracellular growth cycle free from contamination from unincorporated virus}

Preliminary experiments with strains H.F.E.M. and W.C. revealed that with each, when a large inoculum was used, new mature virus could be obtained at $7 \mathrm{hr}$. after inoculation. But, because of the differences in yields and rates of attachment of the two strains, it was decided to give strain W.C. an advantage by inoculating it $1 \mathrm{hr}$. before strain H.F.E.M. and to harvest the membranes $7 \mathrm{hr}$. after the second inoculation.

When harvesting the membrane at $7 \mathrm{hr}$., there is danger of including with the newly matured virus a part of the original inoculum which had remained extracellular. Because both strain H.F.E.M. and strain W.C. were neutralized by the same antiherpes serum, it was decided to bathe the surface of the chorion with this serum after allowing sufficient time for the strains to penetrate the chorionic cells.

\section{Details of the recombination experiment}

The chorio-allantoic membranes of two eggs at the 11th day of incubation were dropped, using $0.05 \mathrm{ml}$. broth. Then $0.1 \mathrm{ml}$. of a suspension of strain W.C. containing $10^{8}$ i.u. was placed on the membrane and after incubation at $35^{\circ}$ 
for $1 \mathrm{hr}$., $0.05 \mathrm{ml}$. of a suspension of strain H.F.E.M. containing $10^{8.4} \mathrm{i} . u$. was added. After incubation for $1 \mathrm{hr}$. more, $0.5 \mathrm{ml}$. specific neutralizing serum was placed on the membrane and the eggs again incubated for another $6 \mathrm{hr}$. The membranes were then removed and washed thrice in sterile saline, pooled and homogenized with alundum and $1.0 \mathrm{ml}$. broth. The material was centrifuged at 2000 r.p.m. and the supernatant fluid collected. In parallel, control eggs were inoculated separately with either parent. These eggs were then treated in the same way as those which were doubly infected.

\section{Isolation and characterization of clones of progeny}

It had been decided to isolate ten clones of the progeny of the mixed infection and five each from the two single infections, then these twenty clones isolated were to be characterized and tested for stability. Such an undertaking would have required large numbers of animals and eggs and have taken a long time. It was, therefore, decided to screen each of the clones on the basis of two characters only, and to investigate fully only those clones whose behaviour differed from the parents.

Isolation of clones. The suspensions obtained from the mixed infection and the two controls were titrated for their content of infective virus. Where fewer than five lesions occurred on a membrane, the lesions were carefully removed and ground separately with a small amount of alundum and $1.0 \mathrm{ml}$. broth. It is recognized that at this stage there was the opportunity for a small amount of virus from other lesions on the same membrane to contaminate the clones, but, it is believed, not sufficient to affect the results of the screening test. Subsequent manoeuvres are assumed to have purified the clones.

Screening test. In order to avoid unnecessary wastage, the screening of clones was carried out in two parts. All strains were first subjected to a short test and subsequently, those which gave unexpected or doubtful results were tested fully by the method of parallel titration.

Short test. Whilst determining mouse virulence ratios, it was noted that the number of i.u. required to kill $50 \%$ of the mice on a particular day after inoculation was fairly characteristic of a strain. If, therefore, the approximate concentration of infective units in a suspension is known, the time that elapses between its inoculation into mice and $50 \%$ of deaths provides a fair indication of mouse virulence. Thus the twenty suspensions obtained from the recombination experiment and controls were each inoculated undiluted into the brains of four to six mice and on to the chorio-allantois of four eggs at a dilution of $10^{-1}$. When the eggs were examined after incubation for $48 \mathrm{hr}$., the lesions were counted and their type noted. The times at which the mice died were also noted. The results are summarized in Table 2. All suspensions derived from strain H.F.E.M. produced LO lesions and all killed mice. Four of those derived from strain W.C. gave S lesions and one gave no lesions at all on the egg. None killed mice. Of the suspensions derived from the mixed infection, one (106a) gave $\mathrm{S}$ lesions and the remainder LO lesions. Only the latter killed mice, but it will be noted that the time taken to kill $50 \%$ was variable. 


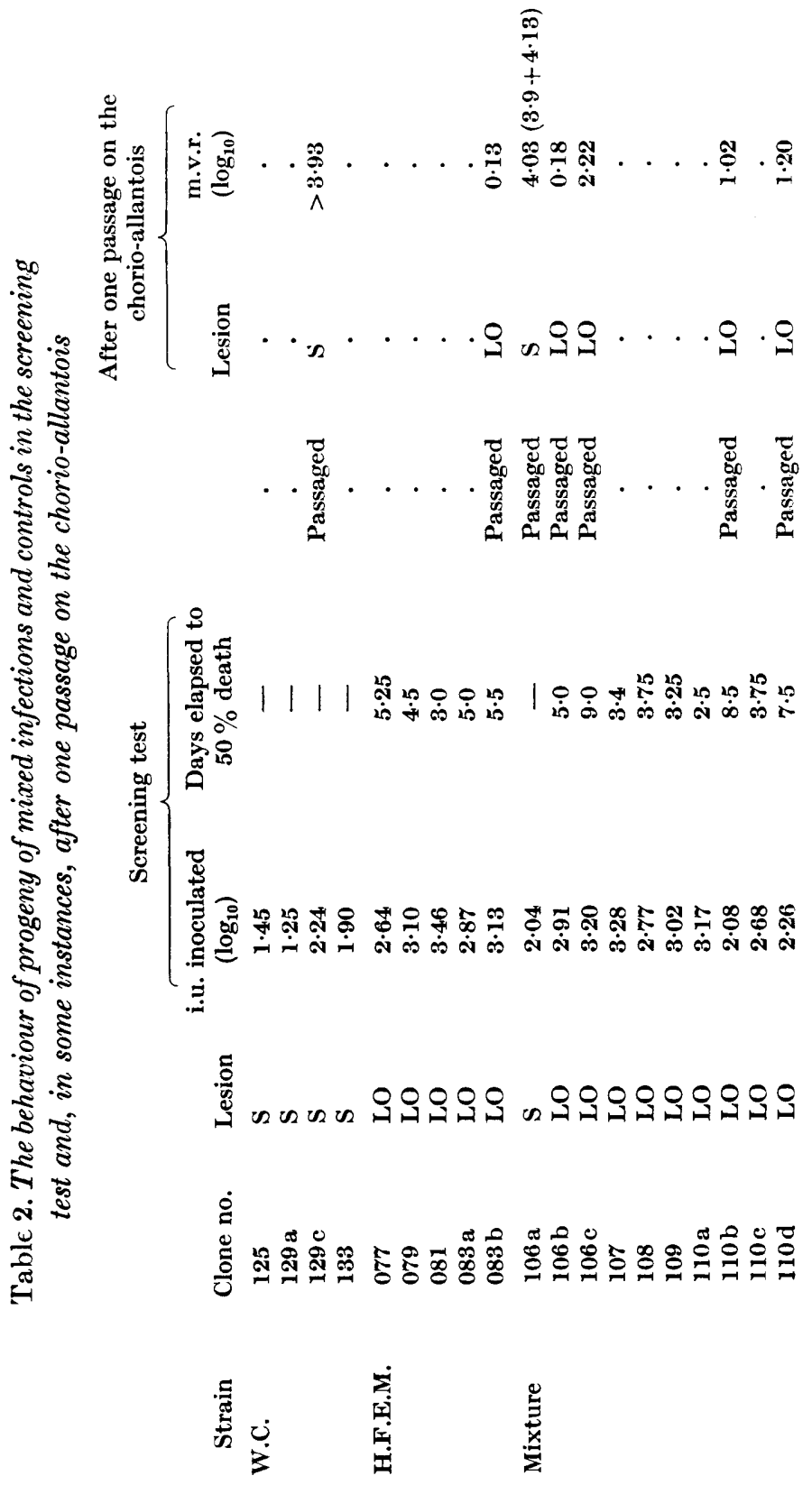


In order to evaluate these results, it is necessary to compare them with the relevant standards. In Fig. 1, the numbers of i.u. of strain H.F.E.M. which give $50 \%$ of deaths at different times are plotted. The points (black dots) were derived from five separate parallel titrations and fall on a characteristic curve. It is not possible to construct a similar curve for strain W.C., but it is known that all values must be greater than $5 \cdot 1 \log _{10}$ i.u.

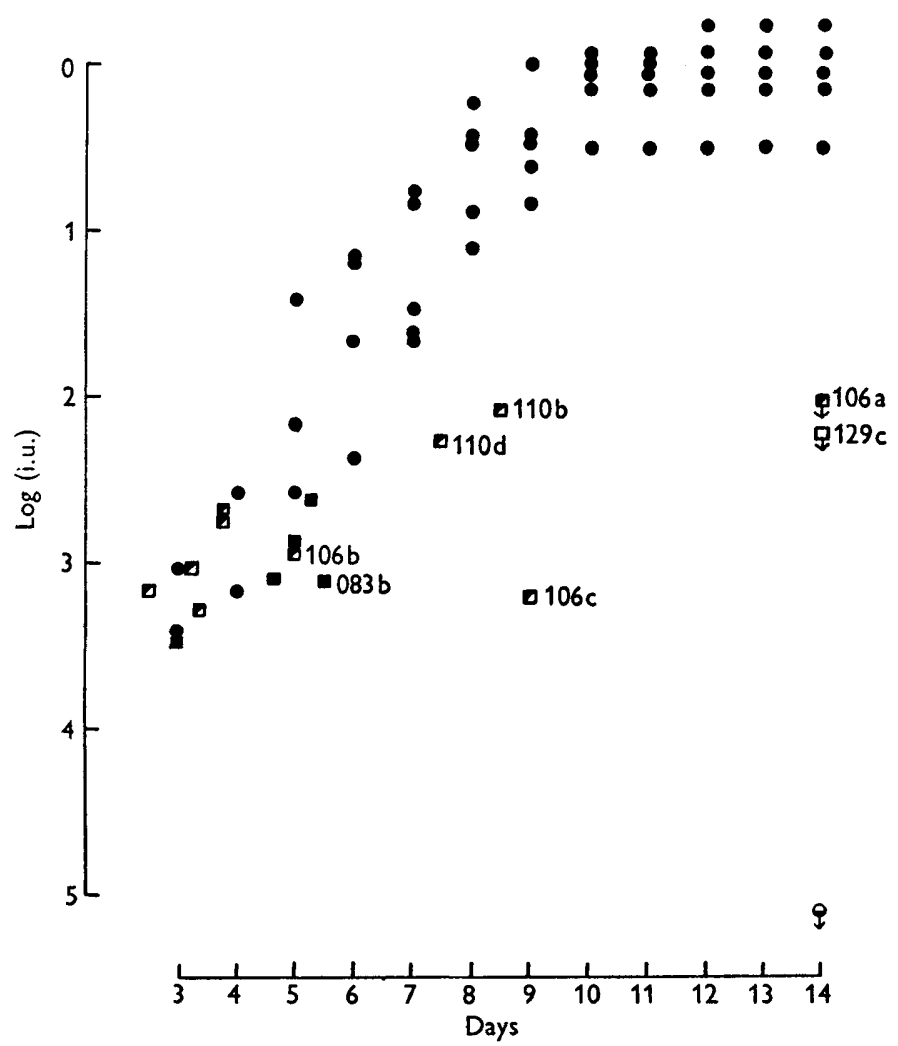

Fig. 1. The number of infective units required to kill $50 \%$ of mice inoculated on particular days for strain H.F.E.M. (O). Superimposed are the results obtained in the screening of progeny of mixed infection $\square$ and parents subjected to similar conditions (H.F.E.M., $\square$; WC, $\square$ ). No mice were killed by strain W.C. ( $\theta)$ in any experiment.

The values given in Table 2 have also been plotted in Fig. 1 (squares). It is to be expected that those which fall on the characteristic curve possess m.v.r. of the order of strains H.F.E.M., whilst those falling below and to the right of the curve possess higher m.v.r. values. In fact, it is obvious that with the exception of the borderline case $083 \mathrm{~b}$, the clones derived from the strain H.F.E.M. control fall within the H.F.E.M. curve. Of the ten clones derived from the mixed infection, six fall on this curve and four $(106 \mathrm{a}, 106 \mathrm{c}, 110 \mathrm{~b}$ and $110 \mathrm{~d}$ ) do not. The above four clones with three others (106 b, H.F.E.M. $083 \mathrm{~b}$, and W.C. $129 \mathrm{c}$ ) were passaged, once on the chorio-allantois, and the resulting suspensions tested by parallel titration. 


\section{Determination of lesion type and m.v.r. after one passage}

The results obtained with the first passage suspensions are summarized on the right of Table 2. In all cases the types of lesion formed were the same as were noted in the short test. The clones H.F.E.M. $083 \mathrm{~b}$ and mixed infection $106 \mathrm{~b}$ both gave m.v.r. values of the order previously found with H.F.E.M. and, as expected, the clones $106 \mathrm{c}, 110 \mathrm{~b}$ and $110 \mathrm{~d}$ gave values which fell between those of the two parents. For the first time, $106 \mathrm{a}$ was inoculated in a sufficiently high concentration to kill mice so that this strain which gives $\mathrm{S}$ type lesions also possesses an m.v.r. value between the parents. It is unfortunate that the only clone of strain W.C. (129c) which was tested had a low concentration of infective virus, but it is significant that whilst this and 106a were inoculated into mice at about the same concentration, mice were only killed by the latter.

\section{Stability of characteristics amongst clones from the mixed infection}

If the alterations in virulence observed are to be ascribed to genetic changes, it is necessary to show that the quality is stable and the characteristic of a pure clone. Accordingly, the clones $106 \mathrm{a}, 106 \mathrm{c}$, and $110 \mathrm{~b}$ were passaged serially on the chorio-allantois. This was performed by the method for isolating pure clones where lesions occurring single on membranes were picked for passage. Between three and five passages were made in this way. During the process no alteration occurred in the type of lesions formed. Suspensions obtained from the final passage were titrated in parallel on eggs and in mice.

The mouse virulence ratios obtained are set out in Table 3 . It is clear that single lesion passage preserved the essential characteristics of the clones. There was no alteration in the type of lesion formed, and 106a and $110 \mathrm{~b}$ obviously retained their characteristic m.v.r. The clone $106 \mathrm{c}$ did show a fall in m.v.r., but as this was less than $1 \mathrm{log}$ unit, it is interpreted as being within the range expected with this test (i.e. $1 \log$ unit).

In view of the foregoing results, it was considered worth while to determine the ratio of attachment of the three clones $106 \mathrm{a}, 106 \mathrm{c}$ and $110 \mathrm{~b}$ and to examine

Table 3. The stability of the character of the lesions produced and m.v.r. given by three substances from the mixed infection after a number of single lesion passages on the chorio-allantois

\begin{tabular}{|c|c|c|c|c|c|}
\hline \multirow[b]{2}{*}{ Substrain } & \multicolumn{2}{|c|}{ First passage material } & \multirow[b]{2}{*}{$\begin{array}{c}\text { Subsequent single lesion } \\
\text { passages (serial numbers } \\
\text { of eggs) }\end{array}$} & \multicolumn{2}{|c|}{ Final passage material } \\
\hline & Lesion & $\begin{array}{c}\text { m.v.r. } \\
\left(\log _{10}\right)\end{array}$ & & Lesion & $\begin{array}{c}\text { m.v.r. } \\
\left(\log _{10}\right)\end{array}$ \\
\hline \multirow[t]{3}{*}{$106 \mathrm{a}$} & $\mathbf{s}$ & $4 \cdot 03$ & $069 \rightarrow 618 \rightarrow 066 \rightarrow 454 \rightarrow 752$ & 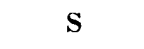 & $3 \cdot 63$ \\
\hline & & & $\searrow_{067 \rightarrow 456 \rightarrow 748}$ & $\mathbf{S}$ & $4 \cdot 02$ \\
\hline & & & $\searrow_{457 \rightarrow 750}$ & $\mathbf{S}$ & $3 \cdot 49$ \\
\hline \multirow[t]{3}{*}{$106 \mathrm{c}$} & LO & $\mathbf{2 \cdot 2 2}$ & $073 \rightarrow 626 \rightarrow 464 \longrightarrow 758$ & LO & 1.79 \\
\hline & & & & LO & $\mathbf{1 \cdot 2 6}$ \\
\hline & & & $463 \rightarrow 756$ & LO & $1 \cdot 35$ \\
\hline $110 \mathrm{~b}$ & LO & 1.02 & $087 \rightarrow 472 \rightarrow 760$ & LO & $1: 45$ \\
\hline
\end{tabular}


their behaviour in rabbits. For both purposes, the suspensions of virus used were obtained from the final single lesion passage.

Rate of attachment to the chorio-allantois. The rates of attachment were determined as before, but only after periods of 30 and $120 \mathrm{~min}$. On the whole, the results obtained were clear. The three suspensions of $106 \mathrm{a}$ showed that the proportions of unattached virus at $30 \mathrm{~min}$. were 38,34 and $38 \%$ and at $120 \mathrm{~min}$. 11,11 and $12 \%$. Those of $106 \mathrm{c}$ were 25,37 and $25 \%$ at 30 min. and 6,6 and $14 \%$ at $120 \mathrm{~min}$., whilst that of $110 \mathrm{~b}$ gave the values $27 \%$ at $30 \mathrm{~min}$. and $11 \%$ at $120 \mathrm{~min}$. It will be seen that while the three suspensions of $106 \mathrm{a}$ gave good agreement, there were two anomalous results with $106 \mathrm{c}$. It has, unfortunately, not been possible to repeat the determinations, but it is considered that the values $37 \%$ after $30 \mathrm{~min}$. and $14 \%$ after $120 \mathrm{~min}$. are at fault. They were obtained with different suspensions (754 and 756) and appear incompatible with all other results with this type of experiment, and have, therefore, been disregarded. A summary of the results is given in Table 4; where they are compared with those previously obtained with the parents. It is clear that of all strains W.C. became attached most slowly to the chorio-allantoic membrane, and the results suggest that $106 \mathrm{a}$ became attached more slowly than $106 \mathrm{c}$, $110 \mathrm{~b}$ and H.F.E.M., all of which became attached at much the same rate.

Table 4. The characteristics of parent strains W.C. and H.F.E.M. and three substances of progeny after single pock passage

\begin{tabular}{|c|c|c|c|c|c|}
\hline \multirow[b]{2}{*}{ Parent strain } & \multirow[b]{2}{*}{ Lesion } & \multirow{2}{*}{$\begin{array}{l}\text { Proportion unattached } \\
\text { to chorio-allantois } \\
30 \text { min. after inoculation } \\
(\%)\end{array}$} & \multirow[b]{2}{*}{$\underset{\left(\log _{10}\right)}{\text { m.v.r. }}$} & \multicolumn{2}{|c|}{ Behaviour in rabbits } \\
\hline & & & & $\mathbf{k}$ & $\mathbf{E}$ \\
\hline $\begin{array}{l}\text { W.C. } \\
\text { H.F.E.M. }\end{array}$ & $\begin{array}{l}\text { S } \\
\text { LO }\end{array}$ & $\begin{array}{l}50 \cdot 5 \\
22\end{array}$ & $\begin{array}{r}<5 \cdot 1 \\
0 \cdot 14\end{array}$ & - & $\overline{+}$ \\
\hline \multicolumn{6}{|l|}{ Progeny } \\
\hline $\begin{array}{r}106 \mathrm{a}(752) \\
(748) \\
(750)\end{array}$ & $\begin{array}{l}\mathbf{S} \\
\mathbf{S} \\
\mathbf{S}\end{array}$ & $\begin{array}{l}38 \\
34 \\
38\end{array}$ & $\begin{array}{l}3 \cdot 63 \\
4 \cdot 02 \\
3 \cdot 49\end{array}$ & $\begin{array}{l}+ \\
+ \\
+\end{array}$ & $\begin{array}{l}- \\
-\end{array}$ \\
\hline $\begin{array}{r}106 \mathrm{c}(758) \\
(754) \\
(756)\end{array}$ & $\begin{array}{l}\text { LO } \\
\text { LO } \\
\text { LO }\end{array}$ & $\begin{array}{l}25 \\
37 \\
25\end{array}$ & $\begin{array}{l}1.79 \\
1 \cdot 26 \\
1 \cdot 35\end{array}$ & $\begin{array}{l}+ \\
+ \\
+\end{array}$ & $\begin{array}{l}+ \\
+ \\
+\end{array}$ \\
\hline $110 \mathrm{~b}(760)$ & ${ }_{\mathrm{K}}^{\text {LO }}$ & $=$ keratitis & $\begin{array}{c}1 \cdot 45 \\
\text { halitis }\end{array}$ & + & + \\
\hline
\end{tabular}

Behaviour in rabbits. Each of the suspensions was inoculated as previously described, on to the cornea of one rabbit. The results (Table 4) were so clear-cut that it appeared unnecessary to use more animals. It is of interest that whilst $106 \mathrm{c}$ and $110 \mathrm{~b}$ both gave keratitis, encephalitis and death, 106a only produced keratitis which ultimately disappeared. This behaviour is intermediate between the two parent strains.

\section{Summary of results}

The two strains H.F.E.M. and W.C. were inoculated together in such a way that double infection of a proportion of host cells was expected. Characteriza- 
tion of ten clones of the progeny revealed that four possessed types of lesion like one or other parent and levels of virulence for mice which were intermediate between those of the parents. With three clones, these characteristics were shown to be stable for three to five single lesion passages. The behaviour of suspensions derived from the last passage is summarized in Table 4, where the results previously obtained with H.F.E.M. and W.C. are also shown for comparison.

\section{DISCUSSION}

Five examples of polygenic inheritance of virulence amongst animal viruses have now been recorded (Burnet \& Lind, 1954; Burnet, 1954). The evidence in favour of this hypothesis rests mainly on the results of recombination experiments where the progeny exhibits a wide distribution in the levels of virulence of individual clones intermediate between those of the parent strains.

The results obtained here suggest a similar phenomenon, but before they can be ascribed to genetic interaction, one must have reasonable evidence that certain assumptions are correct. First, the marker characteristics used must be clear-cut and stable. Secondly, the method of isolating pure clones must be certain. Thirdly, there should be evidence that the conditions imposed by the recombination experiment do not modify either parent when inoculated individually and lastly, pure clones of progeny isolated should remain stable on passage.

Of the marker characteristics employed here, it is clear that the level of virulence for mice, the type of lesion formed and the behaviour of the strains in rabbits all provide clear-cut results. The rate of attachment to the chorioallantois which showed wide differences between the parent strains gave less clear-cut differences amongst the progeny.

Isolation of pure clones by the limiting dilution technique has been discussed fully by Burnet (Burnet \& Lind, 1951). With herpes virus, an advantage is offered in that this virus produces easily visible lesions on the chorio-allantois. It has been assumed that each lesion is caused by only one virus particle. Three circumstances support this view. First, despite contrary reports (Rose, 1952), there exists, within limits, an approximately linear relationship between the dilution of virus suspension inoculated and the number of lesions resulting on the chorio-allantois (Beveridge \& Burnet, 1946). Following the arguments advanced by Dulbecco (1952), this provides good evidence that each lesion is caused by one virus particle. A second hint is provided by the fact that with H.F.E.M., H.F.E., Nag and W.C. one egg infective unit is just sufficient to infect a mouse intracerebrally when the criteria for infection are taken as either death from encephalitis or ability of the inoculated mouse to survive intracerebral challenge with 100 i.u. H.F.E.M. 14 days after inoculation (Wildy, unpublished). This suggests that the infective doses for eggs and mice are the same, and the simplest interpretation is that in each case one virus particle is involved. The third circumstance is provided by analogy with the findings with vaccinia virus (Parker, Bronson \& Green, 1941), which strongly suggested that each lesion was initiated by one virus particle. Although, therefore, there exists no unequivocal evidence that the lesions of herpes 
simplex on the chorio-allantois are initiated by a single virus particle, it is considered a reasonable assumption that this is so.

It is considered most unlikely that the conditions imposed upon parent strains during the recombination experiment would in any way modify their behaviour. It has unfortunately not been possible to characterize fully the ten clones of virus isolated from the control eggs in which parent strains were separately inoculated. It is clear, however, that in every case each parent strain gave rise only to its characteristic type of lesion and that on the basis of the screening test, the five clones of H.F.E.M. behaved typically with regard to their mouse virulence. The mouse virulence of W.C. has not been satisfactorily checked.

It is clear that the progeny of the mixed infection possessed stable characteristics. When the strains were subjected to serial single lesion passage, the types of lesion produced remained stable for each strain. Only in one case (106c) was there any shift in the m.v.r. (see Table 3) and this was commensurate with the variation in the values obtained previously with this test for H.F.E.M. and H.F.E. (cf. Table 1).

Quantitative experiment with animal viruses necessarily lacks precision. With herpes virus, which lacks the in vitro techniques applicable to influenza viruses, there exists no simple method of assessing the concentration of elementary bodies in a suspension. Hence, the expression of mouse virulence depends upon the comparison of two biological functions which have been expressed as the m.v.r. This value as an expression of mouse virulence obviously depends upon the egg infective unit remaining constant. Again, there is no unequivocal evidence that this is so, but the general experience of consistency with chorio-allantoic titrations suggests that it is the case.

The interpretation of the results in terms of genetic recombination is based upon the fact that clones isolated from the first intracellular growth cycle of a mixed infection exhibited stable characteristics which were different from either parent.

Too few isolations were made to infer any particular genetic patterns in herpes simplex virus, but the fact that recombinants were isolated with different degrees of virulence from the parent strains suggests strongly polygenic control of this quality. At the present time, very little is known about the genetic processes occurring in viruses like herpes simplex. It may be significant that the naturally occurring and recombinant strains which have been tested may be arranged so as to form an 'activity gradient' with the strain H.F.E.M. as the most active in all respects and strain W.C. as the least. It may well be that the differences with which we are concerned involve a simple factor 'activity' which depends in some way upon 'dosage' or number of one genetic determinant rather than upon several different genes.

Once the results have been accepted as genetic recombination, it follows that herpes virus resembles influenza virus in its mode of multiplication in that the genome becomes segregated in the early stages of growth. Evidence for the existence of an eclipse phase during the growth of herpes has already been provided (Scott, Coriell, Blank \& Gray, 1953; Wildy, 1954). The inference 
that segregation occurs during the eclipse phase is obvious, but as there exists no evidence to this effect, this remains a probability only. The study on the appearance of soluble complement-fixing antigen during the first intracellular growth cycle of herpes (Wildy \& Holden, 1954) suggested that this occurs with maturation of new virus rather than before, so that this is not thought to be related to the process of segregation and recombination.

It is a pleasure to acknowledge the interest and advice given by Sir Macfarlane Burnet who originally suggested the method of approach used in this work. Grateful acknowledgement is also offered to Miss Lois Larkin without whose technical competence the work could not have been completed. Thanks are also due to Mr G. L. Ada for concentrating suspensions of virus, to Mr Wooding for the photographs and to Miss Lester who drew the figure.

The author is in receipt of the British Memorial Fellowship in Virology.

\section{REFERENCES}

Anderson, S. G. (1954). The growth curve of vaccinia virus on the chorio-allantois. Aust. J. exp. Biol. med. Sci. 32, 633.

Beveridge, W. I. B. \& Burnet, F. M. (1946). The cultivation of viruses and rickettsiae in the chick embryo. Spec. Rep. Ser. med. Res. Coun., Lond. no. 256.

Burnet, F. M. (1954). Virulence in animal viruses. Lancet, ii, 559.

Burnet, F. M., Fraser, K. B. \& Lind, P. E. (1953). Genetic interaction between influenza viruses. Nature, Lond. 171, 163.

Burnet, F. M. \& Lind, P. E. (1951). A genetic approach to variation in influenza viruses. J. gen. Microbiol. 5, 46.

Burnet, F. M. \& Lind, P. E. (1954). Genetics of virulence in influenza viruses. Nature, Lond., 173, 627.

Burnet, F. M. \& Lush, D. (1939a). The inactivation of herpes virus by immune sera. Experiments using the chorio-allantoic membrane technique. J. Path. Bact. 48, 275.

Burnet, F. M. \& Lush, D. (1939b). Studies on experimental herpes infection in mice, using the chorio-allantoic technique. J. Path. Bact. 49, 241.

Cairns, H. J. F., Fazekas de St Groth, S. \& Edney, M. (1952). Quantitative aspects of influenza virus multiplication. J. Immunol. 69, 155.

Delbrück, M. \& Bailey, W. T. (1946). Induced mutations in bacterial viruses. Cold Spr. Harb. Symp. quant. Biol. 11, 55.

Dulbecco, R. (1952). Production of plaques in monolayer tissue culture by single particles of an animal virus. Proc. nat. Acad. Sci. Wash. 38, 747.

Florman, A. L. \& Trader, F. W. (1947). A comparative study of pathogenicity of four strains of herpes simplex virus. J. Immunol. 55, 263.

Hershey, A. D. \& Rotman, R. (1948). Linkage among genes controlling inhibition of lysis in a bacterial virus. Proc. nat. Acad. Sci. Wash. 34, 89.

Hirst, G. K. \& GotTlieb, T. (1953). The experimental production of combination forms of virus. J. exp. Med. 98, 41.

Kilbourne, E. D. \& Horsfall, Jun., F. L. (1951). Studies of herpes simplex virus in new born mice. J. Immunol. 67, 321.

Nagler, F. P. O. (1946). A herpes skin test reagent from amniotic fluid. Aust. J. exp. Biol. Med. Sci. 24, 103.

Parker, R. F., Bronson, L. H. \& Green, R. H. (1941). Further studies of the infectious unit of vaccinia. J. exp. Med. 74, 263.

Perry, B. T., van den Ende, M. \& Burnet, F. M. (1954). Recombination with two influenza B strains in the de-embryonated egg. Aust. J. exp. Biol. Med. Sci. 32, 469. 
Reed, L. J. \& Muench, H. (1938). A simple method of estimating fifty per cent end points. Amer. J. Hyg. 27, 493.

Rose, H. M. (1952). Differences in the capacity of human sera to neutralize herpes simplex virus. J. Immunol. 68, 687.

Scott, T. F. McN., Coriell, L. L., Blank, H. \& Gray, A. (1953). The growth curve of the virus of herpes simplex on the chorio-allantoic membrane of the embryonated hen's egg. J. Immunol. 71, 134.

Tyrrele, D. A., Tamm, O., Forssman, O. C. \& Horsfall, F. L. (1954). A new count of the allantoic cells of the 10 day chick embryo. Proc. Soc. exp. Biol., N.Y. 86, 594.

Wildy, P. (1954). The growth of herpes simplex virus. Aust. J. exp. Biol. Med. Sci. $32,605$.

Wildy, P. \& Holden, H. F. (1954). The complement fixing antigen of herpes simplex virus. Aust. J. exp. Biol. Med. Sci. 32, 621.

Wright, H. D. (1933). The importance of adequate reduction of peptone in the preparation of media for the pneumococcus and other organisms. J. Path. Bact. 37, 257.

\section{EXPLANATION OF PLATE}

Chorio-allantoic membranes of eggs inoculated at the 11th day of incubation after a further period of incubation at $35^{\circ}$ for $48 \mathrm{hr}$ : fig. 1, H.F.E.M., fig. 2, W.C. both magnified, $\times 2$.

(Received 31 March 1955) 
Journal of General Microbiology, Vol. 13, No. 2

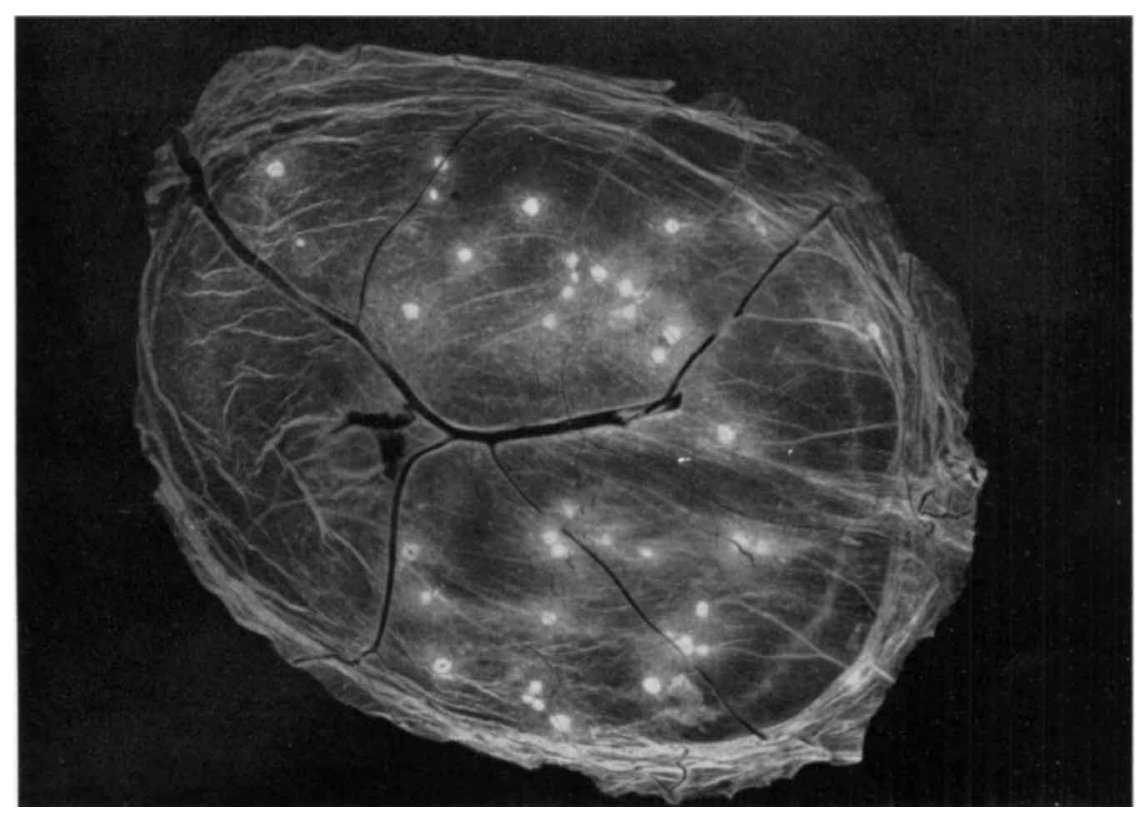

Fig. 1

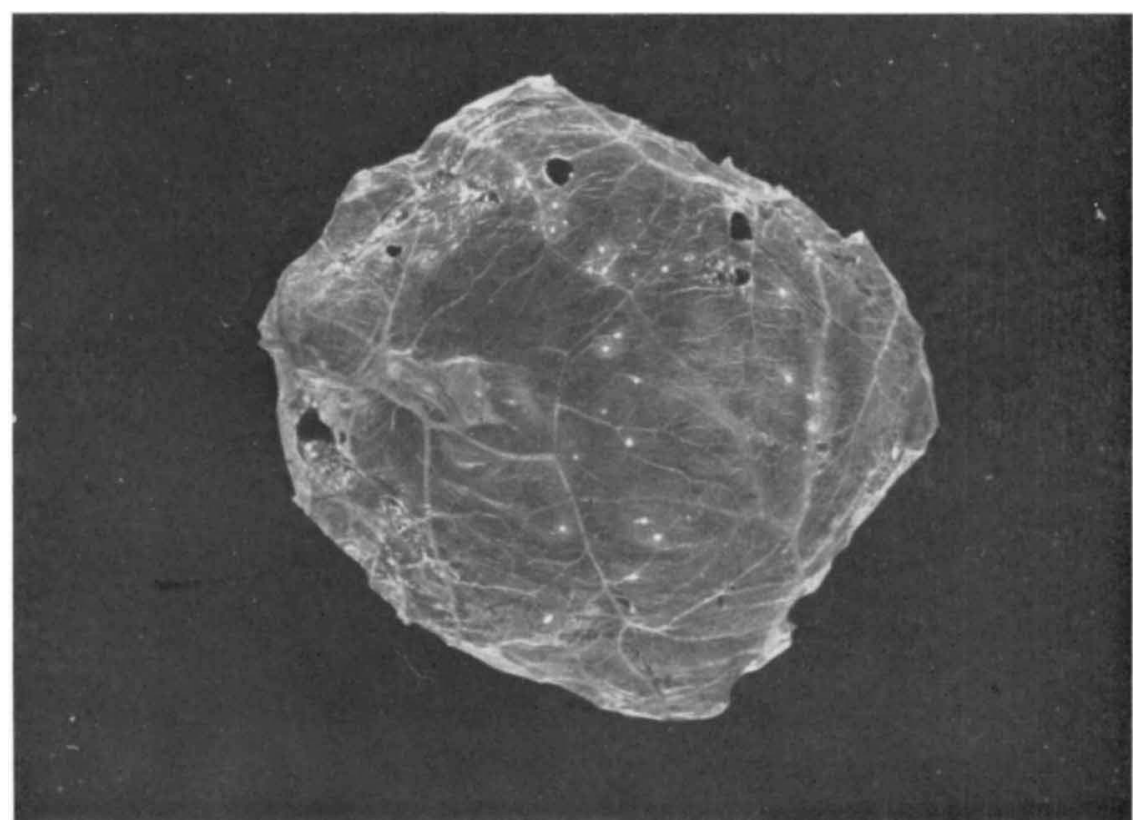

Fig. 2

P. Wildy - Recombination with herpes vires. Plate: 1 